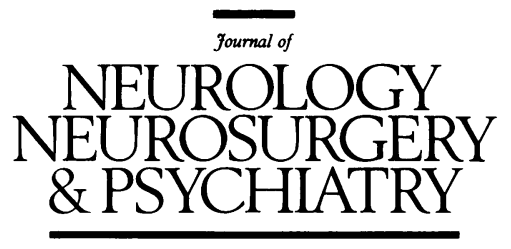

\title{
Editorial
}

\section{Three decades of normal pressure hydrocephalus: are we wiser now?}

Some adults with the clinical triad of gait disturbances, mental deterioration, and urinary incontinence associated with chronic hydrodynamic hydrocephalus will improve after a CSF diversion procedure, even when the CSF pressure is normal at lumbar puncture. ${ }^{12}$ This intriguing paradox was designated normal pressure hydrocephalus (NPH) by Hakim et al, ${ }^{12}$ and has continued to excite both clinicians and researchers seeking pathophysiological mechanisms in CSF hydrodynamics and both the clinical predictors and appropriate tests that would facilitate the accurate selection of candidates for a shunt.

Experiments in chronic hydrocephalic animals and hydrodynamic studies in humans have shown that impairment of CSF flow and episodes of slightly raised CSF pressure are the basic defects in NPH. ${ }^{34}$ Our understanding of persistent or even increasing ventricular enlargement and clinical deterioration despite a "normal" CSF pressure is still incomplete, however. Periods of increased intraventricular pressure, including short lasting $B$ waves, ${ }^{4-8}$ persistence of a slight pressure gradient between the ventricles and the cerebral convexity, ${ }^{9}$ a "waterhammer effect" due to increased CSF pulse pressure waves on the ventricular walls, ${ }^{1011}$ and altered viscoelastic properties of the ventricular wall ${ }^{12}$ have been described as possible contributory mechanisms. It is still unclear whether there is a cause and effect relation between these phenomena and NPH or not.

The site of impaired CSF flow may be situated within the ventricles or in the subarachnoid space. ${ }^{13-18}$ In noncommunicating NPH, partial obstruction to CSF flow within the ventricular system is mainly due to nontumoural aqueduct stenosis. ${ }^{19}$ In communicating NPH, impairment of CSF flow is distal to the 4th ventricle, most often at the level of the basal cisterns ("cisternal block"). About $50 \%$ of communicating hydrocephalus is idiopathic, the other $50 \%$ secondary to subarachnoid haemorrhage, meningitis, cranial trauma, or intracranial surgery. ${ }^{271314}$ There are neither physiological nor pathological arguments to maintain the myth that NPH may be due to defective CSF absorption through the arachnoid villi. This would not lead to ventricular enlargement, as there is no pressure gradient between the ventricles and the convexity. ${ }^{20} 21$

Clinical deterioration is probably due to diminished periventricular blood flow, possibly caused by hydrocephalic compression and stretching of the periventricular arterioles and venules, as shown in experimental hydrocephalus ${ }^{22}$ and in studies on cerebral blood flow in NPH. ${ }^{23-26}$ This would lead to a state of "misery perfu- sion"27; with periventricular blood flow reduced sufficiently to result in axonal dysfunction but not enough to cause irreversible loss of cellular integrity. Narrowed periventricular arterioles due to hyaline vessel wall degeneration in hypertensive patients might be another precipitating factor and would explain why the prevalence of vascular risk factors in NPH is increased. ${ }^{28-30}$ Prolonged periventricular ischaemia would eventually result in myelin disintegration and irreversible axonal loss, possibly explaining why some patients with NPH do not improve after a shunt.

Precise epidemiological data on NPH are lacking. Katzman suggested that the total number of cases in the United States is $10000 \pm 5000$, about one per neurologist. ${ }^{31}$ In published series, NPH accounts for 0 to $6 \%$ of cases of dementia, ${ }^{32} 33$ the variability of these percentages being partly explained by the use of different diagnostic criteria and referral biases. In a recent study, the incidence of clinical improvement after a shunt in 166 patients with presumed NPH was only $2 \cdot 2$ per million persons per year. ${ }^{18}$ Assuming that the incidence of dementia in the same area might be estimated at 600 per million persons per year, shunt responsive $\mathrm{NPH}$ would represent only about $0.4 \%$ of the causes of dementia.

Initially, NPH was thought to be a disease occuring mainly in the presenium ${ }^{7}$ but later many series contained many patients in the sixth decade or older. ${ }^{34-38} \mathrm{~A}$ review of the literature including 21 articles and more than 1000 patients shunted for presumed NPH showed that substantial improvement occurred in about $30 \%$ of idiopathic NPH, in $50-70 \%$ where the aetiology was known. The total number with postsurgical complications was $30-40 \%$, resulting in death or severe residual morbidity in $5-15 \% .{ }^{18}$

\section{Signs and symptoms}

Gait difficulties are the first, in some cases the only, apparent clinical sign, and these are the most likely to improve after shunting. ${ }^{163536}$ There may be difficulty in initiating walking ("magnetic phenomenon"), postural instability and, in more advanced stages, a short-stepped shuffling gait. Hyper-reflexia-mainly in the lower extremitiesand extensor plantar response may be present. These features are not specific, as they may also be seen in other cerebral diseases such as subcortical arteriosclerotic encephalopathy. ${ }^{3940}$ The often used term of "gait apraxia" is controversial ${ }^{41}$ and inappropriate in NPH. ${ }^{42}$ This is illustrated by the fact that patients with NPH may 
execute nearly intact walking movements when minimally supported or when lying down.

The cause of gait impairment in hydrocephalic patients is probably multifactorial, including stretching or destruction of the paraventricular corticospinal fibres, ${ }^{43}$ disconnection of basal ganglia from the frontal cortex, and uninhibited antigravity reflexes and cocontraction of agonists and antagonists during walking. ${ }^{42} 44$

"Dementia" is an unfortunate term with which to designate the mental impairment in NPH, because most patients with shunt responsive NPH have only a slight or moderate mental deficit, ${ }^{16}{ }^{36}$ which would not fit the criteria of dementia as defined in the Diagnostic and statistical manual of mental disorders-revised (DSM-IIIr). ${ }^{45}$ The mental deficit is of the "subcortical" type, resembling that seen in frontal disorders: forgetfulness, inertia, inattention, decreased speed of complex information processing, and impaired ability to manipulate acquired knowledge being the most prominent features. ${ }^{46-48}$ When intellectual loss is predominant in the clinical picture, another cause of dementia should be considered.

The view that the clinical distinction between Alzheimer's disease and NPH is difficult is now hardly tenable, especially in the early stages of these diseases. In NPH there is not only absence of cortical dysfunction, but the pattern of memory deficit is also different: memory functions depending on the functional integrity of the frontal lobes are impaired, resulting in a discrepancy between severely impaired delayed recall and relatively mildly affected or even normal delayed recognition, ${ }^{49}$ as indeed are seen in other diseases with mental deterioration of the subcortical type. ${ }^{50-51}$ This contrasts with Alzheimer's disease, in which encoding deficits and impaired recognition are more prominent. ${ }^{50-51}$ Consequently, the assumption that hydrocephalic amnesia is attributable to enlarged temporal horns and hippocampal dysfunction ${ }^{52}$ is improbable, given the type of memory impairment. When dementia predominates in the clinical picture, concomitant Alzheimer's disease should be suspected and may be confirmed by hippocampal atrophy on $\mathrm{CT}^{53}$ or MRI. ${ }^{54}$

Urinary incontinence is a late sign. An increased urgency, however, is almost always present but often only mentioned when specific inquiries are made. ${ }^{36}$ Urinary incontinence is due to damaged periventricular pathways to the sacral bladder centre, ${ }^{1755}$ with subsequent decreased inhibition of bladder contractions. This has been shown by urodynamic investigations, indicating hyper-reflexia and instability of the bladder detrusor muscle, without evidence of concomitant defective sphincter control. ${ }^{17} 55$

A frequent misconception is that the cause of urinary incontinence is due to a so called "incontinence sans gêne". This is only the case in the most severe forms, when bladder hyper-reflexia is associated with lack of concern for micturition, due to severe frontal lobe dysfunction.

\section{Diagnostic tests}

NEUROPSYCHOLOGICAL ASSESSMENT

The use of brief mental screening tests such as the minimental state examination (MMSE) ${ }^{56}$ may prove inadequate because these are not able to detect slight cognitive impairment, ${ }^{57}$ which is often seen in the mental deficit of the "subcortical" type. Studies that have used the MMSE criteria of dementia for diagnosing $\mathrm{NPH}^{58}$ are flawed by a diagnostic bias, as they excluded all patients with NPH who had mild mental impairment - the very patients with the best surgical prognosis. Even in the early stages of the syndrome, psychometric tests will reveal intellectual decline, provided that the test battery includes tasks that can detect frontal lobe dysfunction, such as the trail making test and the Stroop test. Another advantage of frontal tests is that they are very sensitive in detecting a subtle cognitive decline - for example, in cases where shunt dysfunction is suspected. ${ }^{59}$ Although the test profile may not differentiate NPH from other subcortical dementias, the absence of cortical dysfunction and the "frontal" pattern of mental deficit in NPH would render the diagnosis of Alzheimer's disease improbable.

\section{NEUROIMAGING TECHNIQUES}

Computed tomography has greatly improved the identification of NPH. In "classic" cases, CT usually shows ventricular enlargement out of proportion to cerebral atrophy, including rounded frontal horns and enlarged temporal horns without hippocampal atrophy. ${ }^{60-62}$ Unfortunately, atypical features such as mild or moderate cortical atrophy or periventricular abnormalities of white matter suggestive of ischaemic lesions do not preclude clinical improvement after a shunt. ${ }^{6062}$ Frontal and occipital periventricular lucencies consistent with transependymal CSF absorption are not often seen in NPH. ${ }^{63}$ Potentially misleading is that in both subcortical arteriosclerotic encephalopathy and NPH periventricular lucencies may be selectively located around the frontal horns and that frontal periventricular lucencies due to frontal periventricular ischaemia may be misinterpreted as due to transependymal CSF absorption. ${ }^{17}$

Jack et $a l^{64}$ pointed out that the high sensitivity of MRI in detecting ischaemic white matter lesions may lead to problems in deciding whether these lesions explain the clinical picture or are merely asymptomatic findings in patients who really have NPH. A patient with NPH and an incorrect MRI diagnosis of subcortical arteriosclerotic encephalopathy may have been denied the potential benefit of a shunt. In patients with substantial and global cognitive impairment, MRI may facilitate differentiating Alzheimer's disease from NPH by measuring the mean cross sectional volume of the hippocampal body, which is atrophic in Alzheimer's disease but not in NPH. ${ }^{54}$

T2 weighted images may show a "CSF flow voiding sign" 6566 consisting of a decreased MR signal, mainly in the aqueduct, which correlates with the velocity of pulsatile CSF flow. In shunt responsive communicating $\mathrm{NPH}$, the aqueductal CSF flow velocity may be increased, ${ }^{66}$ but the relevance of this finding is still unclear, as there is no high correlation between a pronounced CSF flow voiding sign and NPH, ${ }^{6768}$ and successful shunts will not necessarily result in a decrease of the CSF flow voiding sign. ${ }^{66}$ Many other MR findings pertaining to NPH reported in small series have not as yet been independently verified.

\section{REMOVAL OF CSF}

Lumbar puncture with removal of $40-50 \mathrm{ml} \mathrm{CSF}$ may be followed by a transient or, in rare cases, prolonged clinical improvement. ${ }^{16970}$ Wikkelsö et al assumed that the degree of postsurgical improvement could be predicted by the degree of improvement after a CSF tap. ${ }^{70}$ Although these results have not been reproduced by others, the CSF tap test is now used worldwide, probably because it is easy, rapid, and cheap. There is increasing evidence, however, that the predictive accuracy of a CSF tap is limited, particularly because of the high rate of false negative results. ${ }^{17}$ Haan and Thomeer ${ }^{71}$ and Hanley et $a l^{72}$ suggest that, even in the case of a "negative" CSF tap test, the effect of continuous external lumbar drainage of about $150-200 \mathrm{ml}$ daily for three to five days 
may accurately predict the outcome after a shunt. This test is technically simple and applicable in most neurological and neurosurgical departments, as disposable equipment is now available. Complications associated with the test, such as radicular inflammation or meningitis, however, may occur. ${ }^{71}$ As the reported series was small and a meaningful postsurgical benefit may be delayed by several weeks or even months, these promising results should be confirmed by a larger multicentre prospective study with long term follow up.

\section{CISTERNOGRAPHY}

Isotope cisternography to assess CSF circulation ${ }^{73}$ was first used by Bannister et al in NPH. ${ }^{74}$ With the advent of CT, CT cisternography ${ }^{75}$ was also used to show disturbed CSF circulation with "reversed CSF flow". Despite the experiences of many investigators that cisternography is an unreliable predictive test and the recent finding that the test did not add to the diagnostic accuracy of combined clinical and CT criteria, ${ }^{76} 77$ cisternography remains one of the most popular tests. ${ }^{78}$ This may be due to the reluctance of clinicians to change their practice, despite the evidence that a particular procedure is unreliable. ${ }^{79}$

\section{MEASUREMENTS OF CEREBRAL BLOOD FLOW AND}

\section{METABOLISM}

It has been suggested that cerebral blood flow studies are of value in predicting the outcome after shunting. Recent cerebral blood flow studies with single photon emission computed tomography (SPECT), ${ }^{23-2680}$ transcranial Doppler sonography of the middle cerebral artery, ${ }^{81} 82$ and measurements of cerebral metabolism with PET ${ }^{83}$ have shown decreased cerebral blood flow and metabolism in NPH, most pronounced in the frontal and the periventricular areas. In some patients with shunt responsive NPH, the cerebral blood flow increased after CSF removal or after a shunt. ${ }^{24}$ Many inconsistencies remain: the areas of impaired cerebral blood flow differ from study to study, ranging from widespread cerebral hypoperfusion to selective ischaemia in the frontal periventricular areas; there is no good correlation between changes in cerebral blood flow and outcome after CSF diversion; at long term follow up recurrence of decreased cerebral blood flow may occur without concomitant clinical deterioration. It is probable that one of the reasons for the variable results is that, in some studies, techniques for measuring cerebral blood flow in patients with NPH were not sensitive enough to detect subtle changes in the frontal periventricular areas.

\section{PRESSURE MONITORING AND HYDRODYNAMIC TESTS}

Continuous intracranial pressure monitoring may show CSF pressure oscillations with a frequency of $0.5-2$ per minute (B waves). ${ }^{5-84}$ The aetiology and pathogenetic role of $\mathrm{B}$ waves are still unclear as they are a physiological phenomenon occurring in healthy persons. ${ }^{85}$ Investigations in centres with CSF hydrodynamic expertise have shown that the occurrence of $B$ waves is much increased in shunt responsive $\mathrm{NPH}$, sometimes exceeding $50 \%$ of the observation time..$^{5-817}$ Unfortunately, the results of continuous intracranial pressure monitoring in less specialised neurosurgical centres are not known, and there is evidence that in many of them, it is not in routine use, mainly due to technical problems or questionable results. ${ }^{78}$

There are still doubts about the reliability of lumbar CSF infusion tests, which measure the resistance of CSF outflow $\left(R_{\text {our }}\right)$ by lumbar or ventricular infusion of artificial CSF. Variable results have been obtained. Some investigators found the test reliable with a high rate of postsurgical improvement when the $R_{\text {out }}$ was higher than 15-20 $\mathrm{mm} \mathrm{Hg} / \mathrm{ml} / \mathrm{min} .{ }^{17} 216186-88$ Others had deceptive experiences with this test. ${ }^{89} 90$ The same holds true for the CSF conductance test $\left(C_{\text {out }}\right.$, the reciprocal of $\left.R_{\text {out }}\right)$, consisting of measuring CSF reabsorption by constant lumboventricular or ventriculoventricular CSF infusions at different CSF pressures. ${ }^{4}$ The test was highly reliable in the hands of some investigators, ${ }^{891}$ but less predictive in other series. ${ }^{24}$ In view of its invasiveness and the need for technical expertise, $C_{\text {out }}$ is not suitable for widespread clinical use.

Unfortunately, the common feature of most studies on the accuracy of ancillary tests for predicting the outcome after shunting is the lack of assessment of the pretest probability of shunt responsiveness based on a global scale combining well established clinical criteria with CT and MR data. ${ }^{92}$ Hence, we do not know which of the reported ancillary tests has the best additional predictive value, and, particularly in the cases of invasive tests, whether the increase in predictive accuracy would be high enough to justify its use in all patients in whom diagnostic doubts remain.

\section{Conclusion}

Are we now wiser after three decades of shunting patients with NPH? In some ways we are. Thanks to 30 years of clinical studies and the availability of new neuroimaging techniques, we are able to identify patients with either probable or improbable shunt responsive NPH with a fairly high rate of diagnostic accuracy. There is now a consensus that, when there is a short history, a known cause of hydrocephalus, predominance of gait disorders, and CT or MRI suggesting hydrodynamic hydrocephalus, about $50-70 \%$ or more will do well after surgery. It is also justified to shunt patients with an unequivocally positive CSF tap test. Shunt response is improbable in patients who are predominantly demented, or who have evidence of substantial cortical atrophy, extensive white matter involvement, or both. Most neurosurgeons will not submit these patients to the risks of a shunting procedure because the chance of a postoperative disaster is higher than that of an unexpected surgical success. ${ }^{17} 18$

Differential diagnostic problems may still arise in some patients with subcortical arteriosclerotic encephalopathy, whose clinical picture may be similar to that of $\mathrm{NPH} .{ }^{93}$ The term "Hakim's clinical triad" is misleading because it may suggest that, in patients with this triad, NPH ranks at the top of the differential diagnostic list. In fact, subcortical arteriosclerotic encephalopathy is much more common than NPH and is the most probable cause of the so called "classical" triad. Although CT and MR imaging now facilitate the differentiation between subcortical arteriosclerotic encephalopathy and NPH, patients with subcortical arteriosclerotic encephalopathy are presumably still shunted for assumed NPH, especially when ventricular enlargement seems disproportionate to the degree of cerebral atrophy.

The main problem, however, is that, despite 30 years of experience, most of us still have management difficulties in patients presenting with communicating NPH who are considered to have a real albeit rather limited chance of improvement after a shunt on the basis of clinical and CT criteria. In this group the substantial benefit: serious harm ratio may be deceptively low, ${ }^{18}$ and labelling idiopathic communicating NPH as a reversible dementia should be considered with extreme reserve.

In this group, disparities of practice remain high, 
ranging from therapeutic nihilism to the pragmatic approach of shunting every patient suspected of NPH ("shunting the patient is the best test"). The urgent need for a simple, cheap, and accurate test for selecting the right patients for a shunt has been repeatedly uttered in review articles and editorials, and the quest is still under way. In the meantime, for clinicians with no access to ancillary investigations with a high predictive accuracy (almost all of us), the reasonable next step when doubts persist after assessment of the clinical, CT or MR, and CSF tap data would be to carry out continuous external lumbar drainage for four to five days, and to shunt only patients with an unequivocal clinical improvement. In view of the low incidence of shunt responsive idiopathic NPH and the presumed high predictive accuracy of external lumbar drainage, ${ }^{71}$ the number of erroneous therapeutic decisions will probably be low and acceptable. A multicentre prospective study assessing the validity and the reproducibility of this relatively simple diagnostic management is currently in progress in The Netherlands.

JAN A L VANNESTE
Department of Neurology,

St Lucasziekenhuis,

fan Tooropstr 164,

1061 AE Amsterdam

The Netherlands

1 Hakim S, Adams RD. The special clinical problem of symptomatic hydrocephalus with normal cerebrospinal fluid pressure. Observations on cerebrospinal fluid hydrodynamics. 7 Neurol Sci 1965;2:307-27.

2 Adams RD, Fisher CM, Hakim S, Ojemann RG, Sweet WH Symptomatic occult hydrocephalus with "normal" cerebrospinal fluid pressure. A treatable syndrome. N Engl ₹ Med 1965;273:117-26.

3 James AE, Burns B, Flor WF, et al. Pathophysiology of chronic communicating hydrocephalus in dogs (canis familiaris). Experimental studies. cating hydrocephalus in dogs
$\exists$ Neurol $S c i$ 1975;24:151-78.

4 Børgesen SE, Gjerris F, Sørensen SC. The resistance to cerebro-spinal fluid absorption in humans. A method of evaluation by lumbo-ventricular perfusion, with particular reference to
cephalus. Acta Neurol Scand 1978;57:88-96.

5 Symon L, Dorsch NWC, Stephans RJ. Pressure waves in so-called low-pressure hydrocephalus. Lancet 1972;2:1291-2.

6 Crockard HA, Hanlon K, Duda EE, Mullan JF. Hydrocephalus as a cause of dementia: Evaluation of computerized tomography and intracranial pressure monitoring. $¥$ Neurol Neurosurg Psychiatry 1977;40:736-40.

7 Pickard JD, Teasdale G, Matheson M, et al. Intraventricular pressure waves-the best predictive test for shunting in normal pressure hydrocephalus. In: Shulman $\mathrm{K}$, Marmarou A, Miller JD, et al, eds. Intracranial pressure IV. Berlin: Springer-Verlag, 1980:498-500.

8 Børgesen SE, Gjerris $F$. The predictive value of conductance to outflow of cerebrospinal fluid in normal pressure hydrocephalus. Brain 1982; 105:65-86.

9 Conner ES, Black PMcL, Foley L. Experimental normal pressure hydrocephalus is accompanied by increased transmantle pressure. $\mathcal{f}$ Neurosurg 1984;61:322-8.

$10 \mathrm{Di}$ Rocco C. Hydrocephalus and cerebrospinal fluid pulses. In: Shapiro K, Marmarou A, Portnoy H, eds. Hydrocephalus. New York: Raven Press, 1984:231-50.

11 Foltz EL. Hydrocephalus and CSF pulsatility: clinical and laboratory studies. In: Shapiro K, Marmarou A, Portnoy H, eds. Hydrocephalus. New York: Raven Press, 1984:337-62.

12 Geschwind $N$. The mechanism of normal pressure hydrocephalus. f Neurol Sci 1968;7:481-93.

13 Ojemann RG, Fisher CM, Adams RD, Sweet WH, New PFJ. Further

experience with the syndro
$f$ Neurosurg $1969 ; 31: 279-94$.

14 Keurosurg 1969;31:279-94. 2nd ed. Philadelphia: FA Davis, 1977:69-92.

15 Pickard JD. Adult communicating hydrocephalus. Br $\mathcal{F}$ Hosp Med 1982; 27:35-44.

16 Pickard JD. Normal pressure hydrocephalus-to shunt or not to shunt. In: Warlow C, Garfield J, eds. Dilemmas in the management of the neurological patient. Edinburgh: Churchill Livingstone, 1984:207-14.

17 Bret P, Chazal J. L'hydrocéphalie chronique de l'adulte. Neurochirurgie 1990;36(suppl 1):1-159.

18 Vanneste JAL, Augustijn P, Dirven C, Tan WF, Goedhart ZD. Shunting normal pressure hydrocephalus: do the benefits outweigh the risks? A multicenter study and literature review. Neurology 1992;42:54-9.

19 Vanneste JAL, Hyman R. Non-tumoural aqueduct stenosis and norma pressure hydrocephalus in the elderly. $\mathcal{F}$ Neurol Neurosurg Psychiatry 1986;49:529-35.

20 Ekstedt J, Fridén H. CSF hydrodynamics for the study of the adult hydrocephalus syndrome. In: Shapiro K, Marmarou A, Portnoy H, eds. Hydrocephalus. New York: Raven Press, 1984:363-82

21 Gjerris F, Børgesen SE. Pathophysiology of the CSF circulation. In Crockard A, Hayward R, Hoff J, eds. Neurosurgery: the scientific basis of clinical practice. Boston: Blackwell Scientific Publications, 1992;1: 146-75.

22 Sato O, Ohya M, Nojiri K, Tsugane R. Microcirculatory changes in In: Shapiro K, Marmarou A, Portnoy H, eds. Hydrocephalus. New York: Raven Press, 1984:215-30.
23 Graff-Radford NR, Rezai K, Godersky JC, Eslinger P, Damasio H, Kirchner PT. Regional cerebral blood flow in normal pressure hydrocephalus. $\mathcal{F}$ Neurol Neurosurg Psychiatry 1987;50:1589-96.

24 Vorstrup S, Christensen J, Gjerris F, Sørensen PS, Thomsen AM, Paulson OB. Cerebral blood flow in patients with normal-pressure Paulson OB. Cerebral blood flow in patients with normal-pressure

25 Mamo HL, Meric PC, Ponsin JC, Rey AC, Luft AG, Seylaz JA. Cerebral blood flow in normal pressure hydrocephalus. Stroke 1987;18:1074-80.

26 Waldemar G, Schmidt JF, Delecluse F, Andersen AR, Gjerris F, Paulson OB. High resolution SPECT with [99m Tc]-d,1-HMPAO in normal pressure hydrocephalus before and after shunt operation. $\mathcal{f}$ Neurol Neurosurg Psychiatry 1993;56:655-64. 27 Astrup J. Energy-requiring cell functions in the ischemic brain.
f Neurosurg 1982;56:482-97.

28 Earnest MP, Fahn S, Karp JH, Rowland LP. Normal pressure hydrocephalus and hypertensive cerebrovascular disease. Arch Neurol 1974; 31:262-6.

29 Koto A, Rosenberg G, Zingesser LH, Horoupian D, Katzman R. Syndrome of normal pressure hydrocephalus: Possible relation to hyperSyndrome of normal pressure hydrocephalus: Possible relation to hyper-
tensive and arteriosclerotic vasculopathy. $\mathcal{F}$ Neurol Neurosurg Psychiatry tensive and arter.

30 Casmiro M, D'Alessandro R, Cacciatore FM, Daidone R, Calbucci F. Risk factors for the syndrome of ventricular enlargement with gait apraxia (idiopathic normal pressure hydrocephalus): a case-contro study. F Neurol Neurosurg Psychiatry 1989;52:847-52.

31 Katzman R. Diagnosis and management of dementia. In: R Katzman, JW Rowe, eds. Principles of geriatric neurology. Philadelphia: FA Davis, 1992: 167-206.

32 Larson EB, Reifler BV, Featherstone HJ, English DR. Dementia in elderly outpatients: a prospective study. Ann Intern Med 1984;100: 417-24.

33 Clarfield AM. The reversible dementias: do they reverse? Ann Intern Med 1988;109:476-86.

34 Laws ER Jr, Mokri B. Occult hydrocephalus: results of shunting correlated with diagnostic tests. In: Keener EB, ed. Clinical neurosurgery.
Baltimore: The Williams and Wilkins Company, 1977;24:316-33.

35 Hughes CP, Siegel BA, Coxe WS, et al. Adult idiopathic communicating hydrocephalus with and without shunting. $\mathcal{F}$ Neurol Neurosurg Psychiatry 1978;41:961-71.

36 Fisher CM. Hydrocephalus as a cause of disturbances of gait in the elderly. Neurology 1982;32:1358-63.

37 Black PMcL, Ojemann RG, Tzouras A. CSF shunts for dementia, incontinence, and gait disturbance. Clin Neurosurg 1985;32:632-51.

38 Petersen RC, Mokri B, Laws ER Jr. Surgical treatment of idiopathic hydrocephalus in elderly patients. Neurology 1985;35:307-11.

39 Ishii $\mathrm{N}$, Nishihara $\mathrm{Y}$, Imamura $\mathrm{T}$. Why do frontal lobe symptoms predominate in vascular dementia with lacunes? Neurology 1986;36:340-5.

40 Bennett DA, Wilson RS, Gilley DW, Fox JH. Clinical diagnosis of Binswanger's disease. $\mathcal{F}$ Neurol Neurosurg Psychiatry 1990;53:961-65.

Binswanger's disease. F Neurol Neurosurg Psychiatry 1990;53:961-65.
41 Nutt JG, Marsden CD, Thompson PD. Human walking and higher-level gait disorders, particularly in the elderly. Neurology 1993;43:268-79.

42 Estanol BV. Gait apraxia in communicating hydrocephalus. $\mathcal{f}$ Neurol Neurosurg Psychiatry 1981;44:305-18.

43 Yakovlev P. Paraplegias of hydrocephalics. Am f Ment Defic 1947;51: 561-76.

44 Knutsson E, Lying-Tunell U. Gait apraxia in normal-pressure hydrocephalus: patterns of movement and muscle activation. Neurology 1985;35:155-60.

45 Diagnostic and statistical manual of mental disorder-revised (DSMIII-r). 3rd edition. Washington DC: American Psychiatric Association, 1987.

46 Gustafson L, Hagberg B. Recovery in hydrocephalic dementia after shunt operation. F Neurol Neurosurg Psychiatry 1978;41:940-7.

47 Thomsen AM, Børgesen SE, Bruhn P, Gjerris F. Prognosis of dementia in normal-pressure hydrocephalus after a shunt operation. Ann Neurol 1986;20:304-10.

48 Cummings JL, Benson DF. Hydrocephalic dementia. In: Dementia: a clinical approach, 2nd edition. Boston: Butterworth Heinemann, 1992: $267-91$.

49 Vanneste JAL. Clinical and neuropsychological characteristics of normal pressure hydrocephalus: an observational study. In: Vanneste JAL: Normal pressure hydrocephalus. Rodopi: University of Amsterdam, 1991:53-62. (PhD Thesis.)

50 Pillon B, Deweer B, Agid Y, Dubois B. Explicit memory in Alzheimer's, Huntington's, and Parkinson's disease. Arch Neurol 1993;50:374-9.

51 Helkala EL, Laulumaa U, Soininen H, Riekkinen PJ. Recall and recognition memory in patients with Alzheimer's and Parkinson's diseases. Ann Neurol 1988;24:214-7.

52 Granholm L. An explanation of the reversible memory defect in hydrocephalus. In: Beks JWF, Bosch DA, Brock M, eds. Intracranial pressure III. Berlin: Springer Verlag 1976:173-5.

53 George AE, DeLeon MJ, Miller J, Kluger A, Smith DC. CT diagnostic features of Alzheimer's disease: importance in the choroidal/hippocampal fissure complex. AfNR Am $\mathcal{F}$ Neuroradiol 1990;11:101-7.

54 Golomb J, de Leon MJ, George AE, et al. Hippocampal atrophy in normal pressure hydrocephalus is associated with severity of cognitive mal pressure hydrocephalus is associated with
impairment. Neurology 1993;43(suppl 2):A211-2.

55 Ahlberg J, Norlén L, Blomstrand C, Wikkelsö C. Outcome of shunt operation on urinary incontinence in normal pressure hydrocephalus predicted by lumbar puncture. I Neurol Neurosurg Psychiatry 1988;51: 105-8.

56 Folstein MF, Folstein SE, Mc Hugh PR. "Mini-mental state": A practical method for grading the mental state of patients for the clinician. f Psychiatry Res $1975 ; 12: 189-98$

57 Nelson A, Fogel BS, Faust D. Bedside cognitive screening instruments. A critical assessment. F. Nerv Ment Dis 1986;174:73-83.

58 Meyer JS, Kitagawa Y, Tanahashi N, et al. Pathogenesis of normal-pressure hydrocephalus-preliminary observations. Surg Neurol 1985;23 121-33.

59 Torkelson RD, Leibrock LG, Gustavson JL, Sundell RR. Neurological and neuropsychological effects of cerebrospinal fluid shunting in children with assumed arrested ("normal pressure") hydrocephalus. f Neurol Neurosurg Psychiatry 1985;48:799-806.

60 Gunasekera L, Richardson AE. Computerized axial tomography in idiopathic hydrocephalus. Brain 1977;100:749-54.

61 Tans JTJ. Differentiation of normal pressure hydrocephalus and cerebral 
atrophy by computed tomography and spinal infusion test. $\mathcal{F}$ Neurol 1979;222:109-18

62 Wikkelsö C, Andersson H, Blomstrand C, Matousek M, Svendsen P. Computed tomography of the brain in the diagnosis and prognosis in normal pressure hydrocephalus. Neuroradiology 1989;31:160-5.

63 Sahuquillo J, Rubio E, Codina A, et al. Reappraisal of the intracrania pressure and cerebrospinal fluid dynamics in patients with the so-called "normal pressure hydrocephalus" syndrome. Acta Neurochir (Wien) 1991;112:50-6

64 Jack CR, Mokri B, Laws ER, Houser OW, Baker HL, Petersen RC. MR findings in normal-pressure hydrocephalus: significance and comparison with other forms of dementia. F Comput Assist Tomogr 1987;11:923-31.

65 Bradley WG, Kortman KE, Burgoyne B. Flowing cerebrospinal fluid in normal and hydrocephalic states: appearance on MR images. Radiolog 1986;159:611-6.

66 Bradley WG, Whittemore AR, Kortman KE, et al. Marked cerebrospinal fluid void: indicator of successful shunt in patients with suspected normal-pressure hydrocephalus. Radiology 1991;178:459-66.

67 Stollman AL, George AE, Pinto RS, de Leon MJ. Periventricular high signal lesions in a single void on magnetic resonance imaging in hydrocephalus. Acta Radiol 1986;369(suppl):388-91.

68 George AE. Chronic communicating hydrocephalus and periventricular white matter disease: a debate with regard to cause and effect. $A \mp N R$ white matter disease: a debate

69 Wikkelsö C, Andersson H, Blomstrand C. The clinical effect of lumbar puncture in normal pressure hydrocephalus. $f$ Neurol Neurosurg Psychiatry 1982;45:64-9.

70 Wikkelsö C, Andersson H, Blomstrand C, Lindqvist G, Svendsen P. Normal Pressure hydrocephalus. Predictive value of the cerebrospina fluid tap-test. Acta Neurol Scand 1986;73:566-73.

71 Haan J, Thomeer RTWM. Predictive value of temporary external lumbar drainage in normal pressure hydrocephalus. Neurosurgery 1988;22: 388-91.

72 Hanley DF, Borel CO, Herdman S. Normal-pressure hydrocephalus. In Johnson RT, ed. Current therapy in neurological disease 3. Philadelphia: BC Decker Inc, 1990:305-9.

$73 \mathrm{Di}$ Chiro G. New radiographic and isotopic procedures in neurological diagnosis. $\mathcal{F} A M A$ 1964;188:524-9.

74 Bannister R, Gilford E, Kocen R. Isotope encephalography in the diagnosis of dementia due to communicating hydrocephalus. Lance 1967;2:1014-7

75 Hindmarsh T, Greitz T. Hydrocephalus, atrophy and their differential diagnosis-CSF dynamics investigated by computer cisternography. In du Boulay GH, Moseley IF, eds. Computerized axial tomography in clinical practice. Berlin: Springer Verlag, 1977:206-12.

76 Vanneste JAL, Augustijn P, Davies G ap AG, Tan WF, Dirven C. Normal pressure hydrocephalus: is cisternography still useful in selecting patients for a shunt? Arch Neurol 1992;49:466-70.

77 Benzel EC, Pelletier AL, Levy PG. Communicating hydrocephalus in adults: prediction of outcome after ventricular shunting procedures. Neurosurgery 1990;26:655-60.

78 Vanneste JAL, van Acker R. Normal pressure hydrocephalus: did literature alter management? $¥$ Neurol Neurosurg Psychiatry 1990;53:564-8.
79 Anonymous. Clinical trials and clinical practice. Editorial. Lancet 1993; 342:877-8.

80 Moretti JL, Sergent A, Louran F, et al. Cortical perfusion assessment with ${ }^{123}$ I-isopropyl amphetamine (123I-IAMP) in normal pressure hydrocephalus (NPH). Eur ₹ Nucl Med 1988;14:73-9.

81 Fritz W, Kalbarczyk H, Schmidt K. Transcranial Doppler sonographic identification of a subgroup of patients with normal pressure hydrocephalus with coexistent vascular disease and treatment failure. Neurosurgery 1989;25:777-80.

82 Droste DW, Krauss JK. Simultaneous recording of cerebrospinal fluid pressure and middle cerebral artery blood flow velocity in patients with suspected symptomatic normal pressure hydrocephalus. $f$ Neurol Neurosurg Psychiatry 1993;56:75-9.

83 Brooks DJ, Beaney RP, Powell M, et al. Studies on cerebral oxygen metabolism, blood flow, and blood volume, in patients with hydrocephalus before and after surgical decompression using positron emission tomography. Brain 1986;109:613-28.

84 Lundberg N. Continuous recording and control of ventricular fluid pressure in neurosurgical practice. Acta Psychiatr Neurol Scand 1960; 36(suppl 149):1-193.

85 Mautner D, Dirnagl U, Haberl R, et al. B-waves in healthy persons. In: Hoff JT, Betz AL, eds. Intracranial pressure VII. Berlin: Springer Verlag, 1989;209-12.

86 Nelson JB, Goodman SJ. An evaluation of the cerebral fluid infusion test for hydrocephalus. Neurology 1971;21:1037-53.

87 Costabile G, Probst C. Hydrocephalus - analysis of 480 infusion tests. In: Avezaat CJ, van Eijndhoven JHM, Maas AIR, Tans JTJ, eds. Intracranial pressure VIII. Berlin: Springer Verlag, 1993:805-10.

88 Price DJ. Attempts to predict the probability of clinical improvement following shunting of patients with presumed normal pressure hydrocephalus. In: Hoff JT, Betz AL, eds. Intracranial pressure VII Berlin: Springer Verlag, 1989:390-3.

89 Delwel EJ, De Jong DA, Avezaat CJJ. The relative prognostic value of CSF outflow resistance measurement in shunting for normal pressure hydrocephalus. In: Avezaat CJ, van Eijndhoven JHM, Maas AIR, Tans JTJ, eds. Intracranial pressure VIII. Berlin: Springer Verlag, 1993: 816, eds.

90 Kosteljanetz M, Westergaard L, Kaalund J, Nehen AM. The significance of outflow resistance measurements in the prediction of outcome after CSF-shunting in patients with normal pressure hydrocephalus. In: Hoff JT, Betz AL, eds. Intracranial pressure VII. Berlin: Springer Verlag, 1989:383-5.

91 Gjerris F, Børgesen SE, Schmidt J, Sørensen PS. Resistance to cerebrospinal fluid outflow in patients with normal pressure hydrocephalus. In: Gjerris F, Børgesen SE, Sørensen PS, eds. Outflow of cerebrospinal fluid. Copenhagen: Munksgaard, 1989:329-38.

92 Vanneste JAL, Augustijn P, Tan WF, Dirven C. Normal pressure hydrocephalus: the predictive value of a global clinical/CT scale. $f$ Neurol Neurosurg Psychiatry 1993;56:251-6.

93 Gallassi R, Morreale A, Montagna P, Sacquegna T, Di Sarro R, Lugaresi E. Binswanger's disease and normal-pressure hydrocephalus. Clinical and neuropsychological comparison. Arch Neurol 1991;48: 1156-9.

\section{NEUROLOGICAL STAMP}

\section{Charles Babbage (1792-1871)}

The British mathematician Charles Babbage's interest in stimulating British scientific activity was not confined to mathematics. $\mathrm{He}$ founded the Royal Astronomical Society in 1820 and the Statistical Society in 1834, and he attacked the British public for their lack of interest in science. His inventions included a type of speedometer and the locomotive cow catcher. He contributed to the setting up of the British postal system in 1840 and compiled the first reliable actuarial tables. $\mathrm{He}$ is best known for his pioneering work in designing and building a mechanical computer.

Although he had theoretical insights into computer design, the prototype of his analytical machine was never completed due to the limitations of mechanical technology available and lack of money. The British Government originally backed his project financially, but then withdrew their support. Babbage put more and more of his own resources into the machine and in this he was assisted by Lord Byron's daughter, Ada, Countess of Lovelace who wrote a program for the analytical engine. With Lady Lovelace he devised a scheme for winning enormous sums of money on horse races but this was not a success and his financial situation continued to deteriorate. Eventually Babbage used up all his own money on the computer project. The incomplete prototype remains in the Science Museum in London. He was philatelically honoured by a stamp issued by Great Britain in 1991 (Stanley Gibbons 1547, Scott 1361).

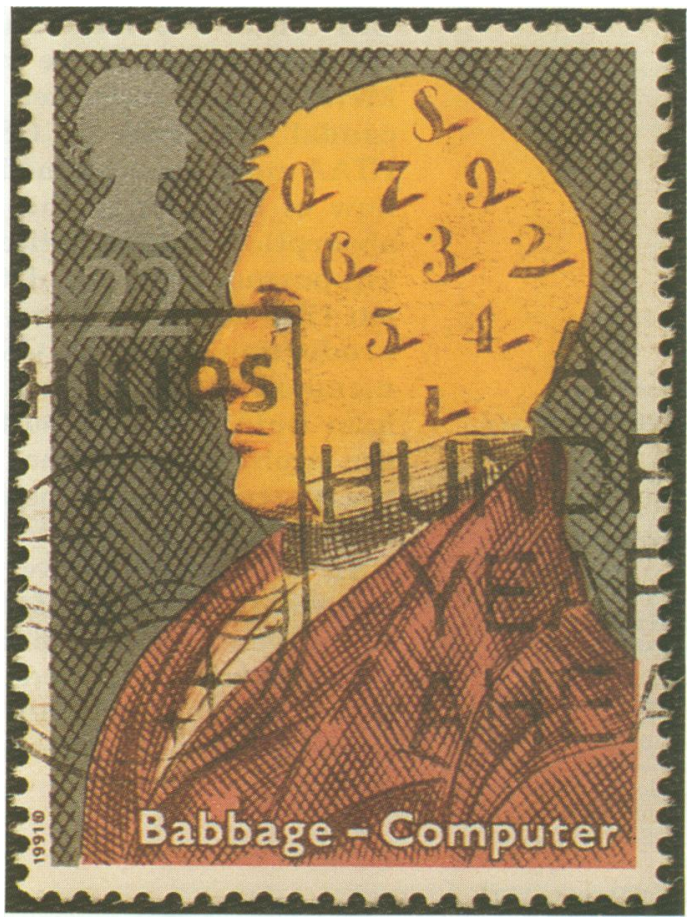

